\title{
CORRECTIONS
}

\section{Author Correction: Biofilm-associated infection by enterococci}

Jun-Hong Ch'ng, Kelvin K. L. Chong, Ling Ning Lam, Jun Jie Wong and Kimberly A. Kline (D)

Nature Reviews Microbiology (2018) https://doi.org/10.1038/s41579-018-0107-z Published online 18 October 2018

In the section on initial attachment and in Figure 1 it was erroneously indicated that enterococcal surface protein (Esp) binds collagen and fibrinogen. The text and figure were changed to remove this binding interaction both online and in the pdf. The authors apologize for any confusion caused.

https://doi.org/10.1038/s41579-018-0128-7 I Published online 20 November 2018

\section{Publisher Correction: Host and viral determinants of influenza A virus species specificity}

Jason S. Long, Bhakti Mistry, Stuart M. Haslam and Wendy S. Barclay

Nature Reviews Microbiology (2018) https://doi.org/10.1038/s41579-018-0115-z

Published online 28 November 2018

In Figure 4, seasonal influenza virus was erroneously indicated as having "HA a2-3 SA preference" instead of "HA drift from population immunity" to represent ongoing evolution of seasonal influenza virus. This has now been corrected in all versions of the Review. The publisher apologizes to the authors and to readers for this error.

https://doi.org/10.1038/s41579-018-0140-y I Published online 18 December 2018 